\title{
Biocompatibility Studies: Their Importance and What Can Be Done
}

\author{
Norhayati Luddin* \\ Department of Restorative Dentistry, School of Dental Sciences, Malaysia
}

ISSN: 2637-7764

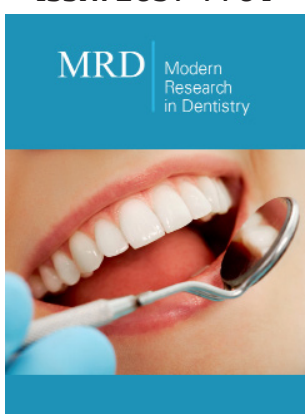

*Corresponding author: Norhayati Luddin Restorative Dentistry (Prosthodontic Unit), School of Dental Sciences, Health Campus, Malaysia

Submission: 非 April 14, 2019

Published: April 17, 2019

Volume 3 - Issue 5

How to cite this article: Norhayati L. Biocompatibility Studies: Their Importance and What Can Be Done. Mod Res Dent. 3(5). MRD.000575.2019. DOI: 10.31031/MRD.2019.03.000575

Copyright@ Norhayati Luddin, This article is distributed under the terms of the Creative Commons Attribution 4.0 International License, which permits unrestricted use and redistribution provided that the original author and source are credited.

\section{Editorial}

Glass Ionomer Cement (GICs) have been used in dentistry since a few decades ago. They are commonly used as restorative materials in pediatric dentistry, as lining and base, fissure sealants and atraumatic restorative treatment (ART) materials. Meanwhile, White Portland Cement has undergone many investigations to determine if it can be a desirable endodontic material as an alternative to the established White Mineral Trioxide Aggregate (MTA). Biocompatibility is one of an ideal properties' criteria for dental materials. It is an important properties to have because they come into contact with dental tissues and may affect the tissue response following the placement of the material into the oral cavity. Hence, the testing on the biocompatibility of any dental material is necessary to ensure that the material is safe for use. Cytotoxicity is one of the methods to investigate a material's biocompatibility. A broad range of in vitro cytotoxicity assays have been developed to evaluate the biocompatibility of various biomaterials. Among these are (3-(4,5-dimethylthiazol-2-yl)-2,5-diphenyltetrazolium bromide (MTT) assay, agar diffusion test, filter diffusion, and pulp and dentine usage tests [13]. Since there are a few methods available for use, it should be borne in mind that the most appropriate method must be selected based on the type and intended use of the sample being evaluated. Apart from that, the availability of equipment in laboratories is another factor to be considered.

MTT assay is an in vitro assay that is use to determine cytotoxicity. It is a sensitive, quantitative and reliable colorimetric assay that measures viability, proliferation and activation of cells [4]. The basic principle of this assay is that MTT yellow tetrazole is reduced to purple formazan by succinate dehydrogenase. An acidified solution is added to dissolve the insoluble purple formazan product into a coloured solution and cytotoxicity is calculated based on the formazan signal generated. It was reported that the cytotoxicity result can be affected by incubation time, MTT concentration, and viable cells that are active metabolically [5]. Many authors reported that GIC is a highly biocompatible material [6-8]. Despite that, some studies revealed an adverse effect of these materials on live cells [9-11]. The differences in biocompatibility might be related to the variability in research protocols. Besides, the use of different types of GIC in the investigations could be the reason for the contradicting findings. Recently, Noorani et al. [12] tested the biocompatibility of nanoHASilica-GIC on Dental Pulp Stem Cells (DPSCs) and compared it with Fuji IX and Fuji II LC. They reported that Fuji IX demonstrated the lowest cytotoxicity, followed by nanoHA-Silica-GIC and Fuji II LC. On the other hand, Ahmed et al. [13] studied the cytotoxicity of two different formulations of White Portland Cements (WPC) on DPSCs and Human Periodontal Ligament Fibroblasts (HPLFs) using MTT assay. They concluded that WPC of different origin may show differences in biological properties with regards to cytotoxicity and human cell types may react differently towards different formulations of WPC. Besides MTT assay, biocompatibility can also be assessed by scanning electron microscope (SEM) studies, as it can display cell morphology and material-cell interaction [14]. In this instance, it can offer the view of how the cells interact with the material of interest, in terms of its attachment and proliferation.

It is documented that cell adhesion is the first step necessary before cells can proliferate, differentiate, and produce an extracellular mineralized matrix on a substrate [15]. Observations in cell shape and the appendages associated with migrating cells such as the 
presence of blebs, filopodia, lamellopodia, or some combination of these could be observed, which may suggest the material's biocompatibility. Despite being a useful imaging tool, SEM has some limitations. It only provides a descriptive and qualitative information about the material's biocompatibility. In this case, the slight or moderate differences between the cytotoxic profiles of different biomaterials usually cannot be detected via SEM. Thus together with SEM, further comparative studies that use other assays such as MTT are essential, to provide an accurate numeric comparison between groups.

\section{References}

1. ISO (1997) Dentistry-preclinical evaluation of biocompatibility of medical devices used in dentistry-Test methods for Dental Materials.

2. ISO B (1999) 10993-5: Biological evaluation of medical devices. Tests for in vitro cytotoxicity.

3. Schmalz G, Hiller KA, Dörter Aslan F (1994) New developments in the filter test system for cytotoxicity testing. J Mater Sci Mater Med 5(1): 4351.

4. Mosmann T (1983) Rapid colorimetric assay for cellular growth and survival: Application to proliferation and cytotoxicity assays. J Immunol Methods 65(1-2): 55-63.

5. Van de Loosdrecht A, Beelen R, Ossenkoppele G, Broekhoven M, Langenhuijsen M (1994) A tetrazolium-based colorimetric MTT assay to quantitate human monocyte mediated cytotoxicity against leukemic cells from cell lines and patients with acute myeloid leukemia. J Immunol Methods 174(1-2): 311-320.

6. Ahmed HMA, Omar NS, Luddin N, Saini R, Saini D (2011) Cytotoxicity evaluation of a new fast set highly viscous conventional glass ionomer cement with L929 fibroblast cell line. J Conserv Dent 14(4): 406-408.
7. Kilic D, Kesim S, Liman N, Sumer Z, Ozturk A (2012) In vitro Comparison of the Effects of Dental Filling Materials on Mouse Fibroblasts. Biotechnology and Biotechnological Equipment 26(4): 3155-3162.

8. Marczuk KG, Łuczaj E, Pawińska M, Hołownia A (2017) Evaluation of the cytotoxicity of selected conventional glass ionomer cements on human gingival fibroblasts. Adv Clin Exp Med 26(7): 1041-1045.

9. Milhem MM, Al-Hiyasat AS, Darmani H (2008) Toxicity testing of restorative dental materials using brine shrimp larvae (Artemia salina). J Appl Oral Sci 16(4): 297-301.

10. Schedle A, Franz A, Rausch Fan X, Spittler A, Lucas T, et al. (1998) Cytotoxic effects of dental composites, adhesive substances, compomers and cements. Dent Mater 14(6): 429-440.

11. Stanislawski L, Soheili Majd E, Perianin A, Goldberg M (2000) Dental restorative biomaterials induce glutathione depletion in cultured human gingival fibroblast: Protective effect of $\mathrm{N}$-acetyl cysteine. J Biomed Mater Res B 51(3): 469-474.

12. Noorani TY, Luddin N, Rahman IA, Masudi SM (2017) In vitro Cytotoxicity evaluation of novel nano-hydroxyapatite-silica incorporated glass ionomer cement. J Clin Diagn Res 11(4): ZC105-ZC109.

13. Ahmed HMA, Luddin N, Kannan TP, Mokhtar KI, Ahmad A (2016) Chemical analysis and biological properties of two different formulations of white portland cements. Scanning 38(4): 303-316.

14. Asgary S, Parirokh M, Eghbal MJ, Ghoddusi J, Eskandarizadeh A (2006) SEM evaluation of neodentinal bridging after direct pulp protection with mineral trioxide aggregate. Aust Endod J 32(1): 26-30.

15. Ahmed HMA, Luddin N, Kannan TP, Mokhtar KI, Ahmad A (2014) Cell attachment properties of Portland cement-based endodontic materials: biological and methodological considerations. J Endod 40(10): 15171523. 